\title{
Mechanism of conjugated linoleic acid and vaccenic acid formation in human faecal suspensions and pure cultures of intestinal bacteria
}

\author{
Correspondence \\ R. John Wallace \\ john.wallace@rowett.ac.uk
}

Received 4 August 2008

Revised 2 October 2008

Accepted 6 October 2008

\author{
Freda M. Mclntosh, ${ }^{1}$ Kevin J. Shingfield, ${ }^{2}$ Estelle Devillard, ${ }^{1} \dagger$ \\ Wendy R. Russell ${ }^{1}$ and R. John Wallace ${ }^{1}$ \\ ${ }^{1}$ Gut Health Division, Rowett Research Institute, Bucksburn, Aberdeen AB21 9SB, UK \\ ${ }^{2}$ MTT Agrifood Research Finland, Fl-31600 Jokioinen, Finland
}

Faecal bacteria from four human donors and six species of human intestinal bacteria known to metabolize linoleic acid (LA) were incubated with LA in deuterium oxide-enriched medium to investigate the mechanisms of conjugated linoleic acid (CLA) and vaccenic acid (VA) formation. The main CLA products in faecal suspensions, rumenic acid (cis-9,trans-11-CLA; RA) and trans9,trans-11-CLA, were labelled at C-13, as were other 9,11 geometric isomers. Traces of trans10,cis-12-CLA formed were labelled to a much lower extent. In pure culture, Bifidobacterium breve NCFB 2258 formed labelled RA and trans-9,trans-11-CLA, while Butyrivibrio fibrisolvens 16.4, Roseburia hominis $\mathrm{A} 2-183^{\top}$, Roseburia inulinivorans $\mathrm{A} 2-192^{\top}$ and Ruminococcus obeumlike strain A2-162 converted LA to VA, labelled in a manner indicating that VA was formed via C13-labelled RA. Propionibacterium freudenreichii subsp. shermanii DSM $4902^{\top}$, a possible probiotic, formed mainly RA with smaller amounts of trans-10,cis-12-CLA and trans-9,trans-11CLA, labelled the same as in the mixed microbiota. Ricinoleic acid (12-OH-cis-9-18:1) did not form CLA in the mixed microbiota, in contrast to CLA formation described for Lactobacillus plantarum. These results were similar to those reported for the mixed microbiota of the rumen. Thus, although the bacterial genera and species responsible for biohydrogenation in the rumen and the human intestine differ, and a second route of RA formation via a 10-OH-18:1 is present in the intestine, the overall labelling patterns of different CLA isomers formation are common to both gut ecosystems. A hydrogen-abstraction enzymic mechanism is proposed that may explain the role of a 10-OH-18:1 intermediate in 9,11-CLA formation in pure and mixed cultures.

\section{INTRODUCTION}

Since Pariza and colleagues (Ha et al., 1987; Pariza, 2004) first identified the anticarcinogenic component of beef as rumenic acid (cis-9,trans-11 conjugated linoleic acid, RA), a conjugated isomer of linoleic acid (cis-9,cis-12-18:2, LA), considerable research has been directed towards understanding the formation, physiological effects and potential health benefits of conjugated linoleic acid (CLA; of which $\mathrm{RA}$ is one stereoisomer) in a range of biological models (Kritchevsky, 2000; Wahle et al., 2004; Bauman et al., 2005). Isomers of CLA were first discovered as intermediates during the metabolism of LA to stearic acid (18:0, SA) by ruminal bacteria (Polan et al., 1964; Harfoot

\footnotetext{
Abbreviations: CLA, conjugated linoleic acid; DMOX, 4,4-dimethyloxazoline; FAME, fatty acid methyl esters; HFA, hydroxy fatty acid; LA, linoleic acid; MPE, mol\% excess; RA, rumenic acid; SA, stearic acid; VA, vaccenic acid.

tPresent address: ADISSEO France S.A.S., Route de Chamblet, 03600 Commentry, France.
}

\& Hazlewood, 1997). Subsequently it was found that LA was also converted to RA by human intestinal bacteria (Kamlage et al., 1999; Coakley et al., 2003; Devillard et al., 2007). Thus, in addition to systemic health benefits from CLA in the diet, CLA formation in the human intestine could promote health. It is therefore important to understand how CLA is formed and metabolized by intestinal bacteria.

CLA formed in the intestine might be absorbed and contribute to systemic CLA. However, experiments with germ-free rats inoculated with a human faecal microbiota and fed a diet enriched with sunflower-seed oil indicated that no benefit accrued in terms of tissue concentrations of CLA (Kamlage et al., 1999). Even if CLA absorption from the intestine is minimal, there may be in situ benefits from intestinal CLA production, however. In mouse models of inflammatory bowel disease, CLA was shown to exhibit anti-inflammatory properties via endoplasmic and nuclear mechanisms (Bassaganya-Riera et al., 2002, 2004). Further studies have demonstrated that CLA exerts anti-carcino- 
genic activity in the rat colon (Nichenametla et al., 2004) and exhibits anti-proliferative properties on the growth of human colon cancer cells in vitro (Kemp et al., 2003). Therefore, mechanisms by which CLA might be delivered to and formed in the intestine have important implications for long-term human health.

The precise isomer(s) that is formed has importance too, given the very different biological effects of RA and other isomers, particularly trans-10,cis-12-CLA (Pariza, 2004; Bauman et al., 2005). Such information could have particular relevance to patients using the slimming drug tetrahydrolipstatin (orlistat; Hauptman et al., 2000) or similar agents that prevent lipid absorption in the human small intestine. Large amounts of lipid reach the large intestine in patients using orlistat, sometimes with deleterious consequences (Chanoine et al., 2005). Conversion of LA to RA under such circumstances might be beneficial, but the formation of 10,12 isomers detrimental (Pariza, 2004; Bauman et al., 2005).

Given these concerns, we have re-examined the mechanism of CLA formation by intestinal bacteria, using methods employed recently to establish the mechanisms involved in CLA isomer formation by ruminal bacteria (Wallace et al., 2007). The rumen seems to possess a single group of bacteria, closely related to Butyrivibrio fibrisolvens, that play a predominant role in biohydrogenation of dietary fatty acids (Polan et al., 1964; Harfoot \& Hazlewood, 1997; Wallace et al., 2006). In contrast, several colonic species, of which Roseburia would usually be most numerous, form
RA and/or vaccenic acid (VA) in the human intestine (Devillard et al., 2007). Furthermore, some Roseburia spp. form 10-OH-18:1 rather than RA from LA (Devillard et al., 2007). This hydroxy fatty acid then serves as a substrate for RA synthesis by other species in the mixed microbiota. Thus, there appeared to be two potential routes of RA formation in the human intestine (Fig. 1). This investigation was undertaken to establish the relative importance of the different mechanisms of formation of different CLA isomers by mixed faecal microbiota and also pure cultures of intestinal bacteria, and to elucidate the molecular mechanism of formation of different CLA isomers.

\section{METHODS}

Incubations with suspensions of mixed human faecal bacteria. Faecal samples were obtained from omnivorous volunteers A, C and $\mathrm{D}$ aged 31 to 39 years, all consuming Western-style diets, and a vegetarian, volunteer B, aged 55 years. Freshly voided faeces were collected in sterile containers, and stored on ice for a maximum of $1 \mathrm{~h}$ before being incubated with LA (Sigma). Faecal samples were homogenized, and subsamples (between 2 and $4 \mathrm{~g}$ wet weight) were transferred to sterile $50 \mathrm{ml}$ tubes and diluted in $0.1 \mathrm{M}$ potassium phosphate buffer, $\mathrm{pH} 7.0$, made up in $40: 50(\mathrm{v} / \mathrm{v})$ water/deuterium oxide ( $99.8 \%$ deuterium-enriched water; Norsk Hydro) to a final concentration of $10 \%$ (wet w/v). Incubations were carried out under $\mathrm{CO}_{2}$ in $12.5 \times 1.6 \mathrm{~cm}$ glass tubes, closed with screw caps fitted with butyl rubber septa (Bellco Biotechnology). An emulsion of LA in water $\left(25 \mathrm{mg} \mathrm{ml}^{-1}\right)$ was prepared by sonication and $100 \mu \mathrm{l}$ was added to each tube. Five millilitres of $10 \%(\mathrm{v} / \mathrm{v})$ suspension was added, and the tubes were incubated at $37{ }^{\circ} \mathrm{C}$. Subsamples $(1 \mathrm{ml})$ were removed after 0,1 and $4 \mathrm{~h}$, transferred into clean tubes and heated at $100{ }^{\circ} \mathrm{C}$

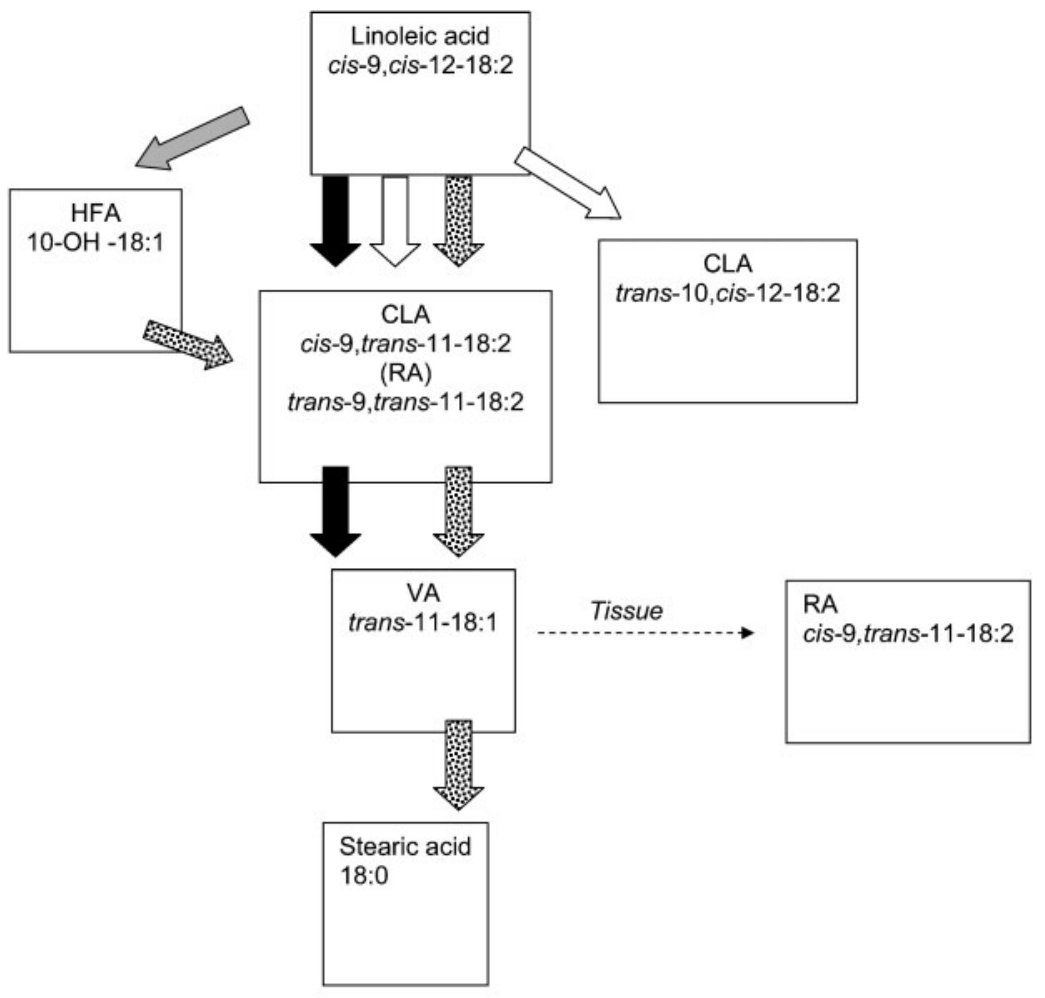

Fig. 1. LA metabolism by human faecal bacteria, adapted from Devillard et al. (2007). The white arrows represent the bacterial activity of Lactobacillus, Propionibacterium and Bifidobacterium species leading to the formation of CLA. The grey arrows represent the bacterial activity of some Lactobacillus, Propionibacterium and Bifidobacterium species, some Clostridium-like bacteria of the clusters IV (e.g. Eubacterium siraeum) and XIVa (e.g. Roseburia intestinalis and Ros. faecis) leading to the formation of HFA. The black arrows represent the bacterial activity of Clostridium-like bacteria of cluster XIVa leading to the formation of VA (e.g. Ros. hominis and Ros. inulinivorans). The dotted arrows represent activities observed in faecal microbiota, but for which the bacterial species responsible are still unknown. HFA, hydroxy fatty acid; CLA, conjugated linoleic acid, of which rumenic acid (RA) is one geometric isomer; VA, vaccenic acid. 
for $10 \mathrm{~min}$. Heated samples were stored at $-20{ }^{\circ} \mathrm{C}$ prior to lipid extraction and fatty acid determinations.

To establish the possible role of hydroxy fatty acids (HFA) as a precursor to RA formation and establish the ability of human microbiota to metabolize HFA, similar incubations were carried out with ricinoleic acid (cis-9,12-hydroxy-18:1).

Bacteria and growth conditions. The bacteria selected in this study are known to metabolize LA (Devillard et al., 2007). Bifidobacterium breve NCFB 2258 was isolated originally from the human infant intestine (Coakley et al. 2003). Butyrivibrio fibrisolvens 16/4 was isolated from human faeces (Rumney et al., 1995). Roseburia hominis $\mathrm{A} 2-183^{\mathrm{T}}$ and Roseburia inulinovorans $\mathrm{A} 2-194^{\mathrm{T}}$ were isolated in a study of butyrate producers from human faeces (Barcenilla et al., 2000) and subsequently reclassified (Duncan et al., 2006). Strain A2-162 was isolated in the same study; based on 16S RNA phylogenetic analysis it is closely related to Ruminococcus obeum (Duncan et al., 2007). Propionibacterium freudenreichii subsp. shermanii DSM $4902^{\mathrm{T}}$ is the type strain of this species (obtained from DSMZ, Deutsche Sammlung von Mikroorganismen und Zellkulturen $\mathrm{GmbH}$, Braunschweig, Germany), originally isolated from cheese (Van Niel, 1928) and considered to be a potential probiotic organism.

The growth media were based on the liquid form of M2 medium (Hobson, 1969). All transfers and incubations were carried out under $\mathrm{O}_{2}$-free $\mathrm{CO}_{2}$ at $37^{\circ} \mathrm{C}$ in Bellco tubes as described previously (Devillard et al., 2007). Inoculum volumes were $5 \%(\mathrm{v} / \mathrm{v})$ of a fresh culture into $5 \mathrm{ml}$ of medium. One batch of medium was made up using unlabelled water, the other prepared with $50 \%(\mathrm{v} / \mathrm{v})$ deuterium oxide. LA was added to a final concentration of $50 \mathrm{mg} \mathrm{l}^{-1}$. In other cultures, ricinoleic acid (cis-9-12-OH-18:1) was added to the same concentration. Fatty acids were prepared as a separate solution, sonicated for $4 \mathrm{~min}$ in a small volume of medium and added to the medium before dispensing and autoclaving. Triplicate $5 \mathrm{ml}$ cultures were grown for $24 \mathrm{~h}$. Subsamples $(1 \mathrm{ml})$ were removed for protein analysis (Herbert et al., 1971) and analysis of the deuterium enrichment in water. Thereafter, $100 \mu \mathrm{l}$ of nonadecanoic acid (200 $\mathrm{mg} \mathrm{l}^{-1}$ in methanol) was added and the tubes were stored at $-70{ }^{\circ} \mathrm{C}$ and subsequently freeze-dried.

Fatty acid extraction and analysis. Extraction of total fatty acids, preparation of fatty acid methyl esters (FAME) and 4,4-dimethyloxazoline (DMOX) derivatives and analysis by GC-MS were performed using standard procedures (Wallace et al., 2007). Enrichment in the $\mathrm{m} / \mathrm{z}(\mathrm{m}+1),(\mathrm{m}+2)$ and $(\mathrm{m}+3)$ isotopomers (molecular ion $+1+2$ and +3 , respectively) was determined by GC-MS of FAME (Wallace et al., 2007). Analysis of DMOX derivatives by GC-MS was used to identify the position of deuterium labelling in the fatty acid moiety. Enrichment in water was determined by gas isotope ratio mass spectrometry (GIRMS) (Wallace et al., 2007).

Data analysis. Three replicate measurements were made in incubations with faecal suspension samples from each of four human donors. Experimental data were analysed by ANOVA for repeated measures with a model that included the fixed effect of incubation time and random effects of volunteer assuming a compound symmetry covariance structure using the mixed linear model procedure of Statistical Analysis Systems software package version 8.2 (SAS Institute). This experimental design accounts for potential autocorrelation between sequential measurements. Measurements of fatty acid concentrations over time during incubation of LA with pure cultures of intestinal bacterial were analysed by ANOVA for repeated measures with a model that included the fixed effect of incubation time and random effects of replicate assuming a compound symmetry covariance structure. Least-square means $\pm \mathrm{SE}$ are reported and effects were considered significant at $P<0.05$. Enrichment of $(m+1)$ isotopomers was calculated from the $\mathrm{m} / z$ ratios at $\mathrm{m}, \mathrm{m}+1, \mathrm{~m}+2$ and $\mathrm{m}+3$ by deconvolution according to Campbell (1974). Natural abundance was calculated from the isotopomer distribution of LA in zero-time samples.

\section{RESULTS}

\section{Metabolism of LA in faecal suspensions}

The rate of disappearance of LA in faecal suspensions was similar during incubations with different samples, declining by about two-thirds in $4 \mathrm{~h}$ from an initial concentration of $500 \mathrm{mg} \mathrm{l}^{-1}$, resulting in the accumulation of CLA isomers and smaller concentrations of VA (Fig. 2). However, the background concentration of SA varied between samples (Fig. 2). Concentrations of SA increased with time in the sample from volunteer $B$, the vegetarian, which also exhibited the highest zero-time SA concentrations.

Detailed analysis of the distribution of CLA isomers synthesized after $4 \mathrm{~h}$ incubations with LA revealed that RA was the most abundant isomer, with lower concentrations of trans-9,trans-11-CLA (on average $17 \%$ of RA concentrations) also being formed (Table 1). Trace amounts of trans-10,cis-12-CLA were also present, but at concentrations below $3 \%$ of total CLA.

Mass spectra of FAME prepared from samples collected after $4 \mathrm{~h}$ incubations indicated that 9,11 geometric isomers of CLA were labelled at $\mathrm{m}+1$. Independent analysis of the enrichment in water allowed the ratio of moles per cent excess (MPE) in samples to be compared with the MPE of water. All samples of water had a similar enrichment $(46.0 \%$, SE $0.36 \%)$. Mean labelling (MPE sample/MPE water) of 9,11 geometric CLA isomers was 0.689 , SE 0.042 (Table 1) whilst labelling at $\mathrm{m}+2$ was not detected. In contrast, mean labelling at $\mathrm{m}+1$ for trans-10,cis-12-CLA was 0.310 , SE 0.056 . There was no evidence of differences in labelling at $\mathrm{m}+1$ in samples collected at 1 or $4 \mathrm{~h}$ (data not presented). Enrichment of VA and SA end products could not be determined due to their high concentrations in zero-time samples.

The mass spectrum of the DMOX derivative of RA (Fig. 3) indicated enrichment in ion fragments from the molecular ion above $\mathrm{m} / \mathrm{z}$ 262. The occurrence of ion fragment isotopomers with $\mathrm{m} / z$ lower than 262 was comparable to the natural abundance of about $20 \%$ MPE. These data provide clear evidence that deuterium was labelled on C-13 of the fatty acid moiety (Fig. 3). Mass spectra of other 9,11 geometric CLA isomers revealed a similar pattern of enrichment as indicated by GC-MS analysis of the DMOX derivative of trans-9, trans-11 CLA (Fig. 3). Due to the low concentration of trans-10,cis-12-CLA following the conversion of FAME to DMOX derivatives, it was not possible to identify the position of the small amount of label.

\section{Formation of CLA and VA by pure cultures of intestinal bacteria}

Six bacterial species shown to metabolize LA (Devillard et al., 2007) were grown in the presence of $50 \mathrm{mg} \mathrm{LA} \mathrm{l}^{-1}$ in 


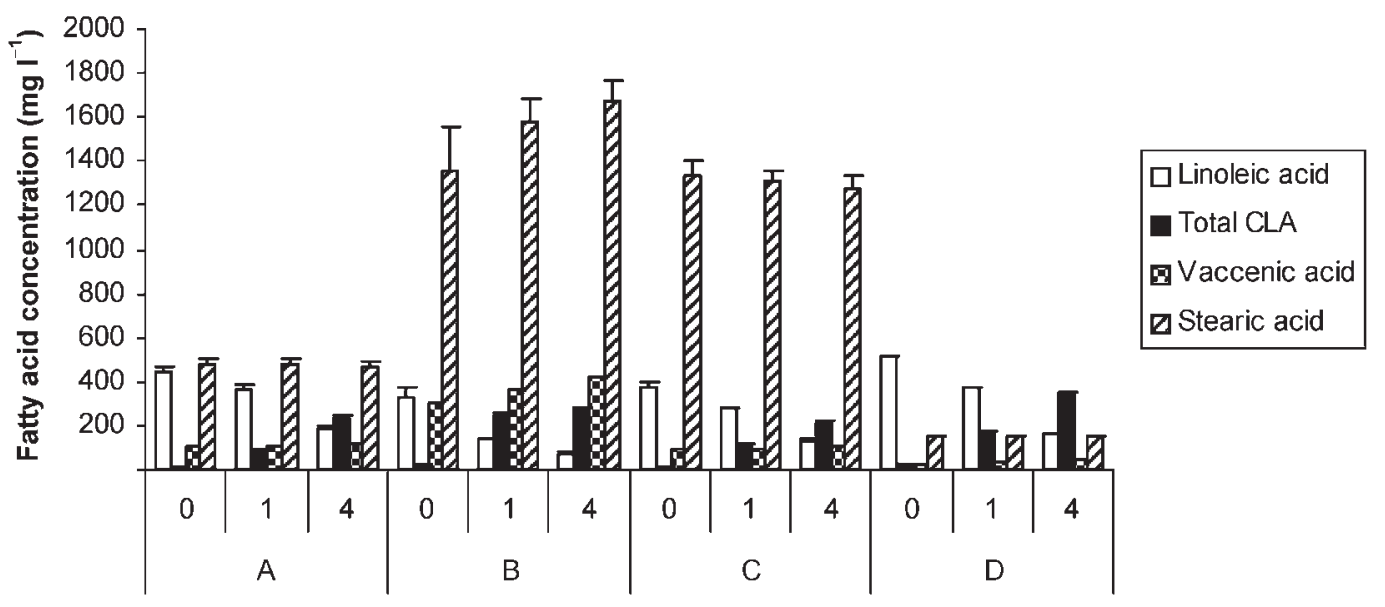

Fig. 2. LA metabolism in suspensions of faecal bacteria from four human volunteers, A-D. Samples were removed at 0,1 and $4 \mathrm{~h}$ for fatty acid analysis. Mean incubation protein content 8.6, SE 2.1, $\mathrm{mg} \mathrm{ml}^{-1}$. Values represent the means of three incubations. Mean SE values were 15.2, 7.29, 12.3 and $59.4\left(\mathrm{mg} \mathrm{l}^{-1}\right)$ for linoleic acid, total CLA, vaccenic acid, and stearic acid, respectively. The initial concentration of LA was $500 \mathrm{mg} \mathrm{I}^{-1}$.

deuterium oxide-enriched medium and samples were collected for fatty acid determinations in the stationary phase. Bif. breve and P. freudenreichii subsp. shermanii produced RA as the predominant product, with smaller concentrations of trans-9, trans-11-CLA also being formed (Table 2). The latter species also produced a small quantity of trans-10,cis-12-CLA. LA was metabolized to VA in the four other species, with only minor amounts of CLA being detected. No SA was formed by any culture during incubations with LA.
The MPE enrichment of deuterium in the medium water was determined as $45.2 \%$, SE $1.25 \%$. The RA formed by $P$. freudenreichii subsp. shermanii was labelled 0.601, SE 0.025, in the $\mathrm{m}+1$ isotopomer, while the trans-9,trans-11 isomer was also labelled to a similar extent (Table 2). Labelling was 0.011 , SE 0.004 , in the $\mathrm{m}+2$ isotopomer. The other isomer formed, trans-10, cis-12-CLA, was unlabelled. Values in Bif. breve cultures were similar for RA, but a higher enrichment was determined for trans-9, trans-11-CLA (Table 2). The mass spectrum of labelled RA produced by pure cultures

Table 1. Concentrations and enrichment in $m+1$ isotopomers of CLA formed from LA in mixed faecal bacteria suspended in buffer containing deuterated water

The initial concentration of LA was $500 \mathrm{mg} \mathrm{l}^{-1}$. The mean mol\% excess (MPE) enrichment in water was 46.0, SE 0.36 . Values are means \pm SE $(n=3)$ after $4 \mathrm{~h}$ incubations with LA. Mean \pm SE concentration in $0 \mathrm{~h}$ incubations were $12.3 \pm 3.00,0.57 \pm 0.176,0.57 \pm 0.060,1.69 \pm 1.883$ and $2.40 \pm 1.174 \mathrm{mg}^{-1}$ for cis-9, trans-11 (RA), trans-9, cis-11, trans-10,cis-12, cis-9, cis-11 and trans-9,trans-11, respectively.

\begin{tabular}{|c|c|c|c|c|c|c|c|c|c|c|}
\hline \multirow{2}{*}{ Volunteer } & \multicolumn{10}{|c|}{ Concentration $\left(\mathrm{mg} \mathrm{l}^{-1}\right)$} \\
\hline & \multicolumn{2}{|c|}{ cis-9,trans-11 (RA) } & \multicolumn{2}{|c|}{ trans-9, cis-11 } & \multicolumn{2}{|c|}{ trans-10,cis-12 } & \multicolumn{2}{|c|}{ cis-9,cis-11 } & \multicolumn{2}{|c|}{ trans-9,trans-11 } \\
\hline A & 185 & 14.5 & 4.4 & 0.53 & 6.1 & 0.36 & 7.8 & 0.51 & 30.5 & 2.76 \\
\hline B & 201 & 14.5 & 5.4 & 0.90 & 2.4 & 0.09 & 15.6 & 1.43 & 44.5 & 6.78 \\
\hline $\mathrm{D}$ & \multicolumn{10}{|c|}{ MPE ratio (MPE in CLA isomer/MPE in water) } \\
\hline A & 0.746 & 0.0090 & 0.605 & 0.0028 & 0.143 & 0.0661 & 0.670 & 0.0689 & 0.740 & 0.0082 \\
\hline B & 0.750 & 0.0065 & 0.700 & 0.0455 & 0.378 & 0.0264 & 0.453 & 0.0378 & 0.774 & 0.0147 \\
\hline $\mathrm{C}$ & 0.758 & 0.0009 & 0.633 & 0.0218 & 0.291 & 0.0135 & 0.771 & 0.0198 & 0.762 & 0.0182 \\
\hline
\end{tabular}




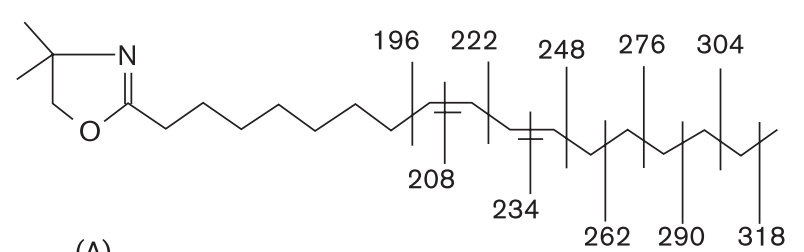

(A)

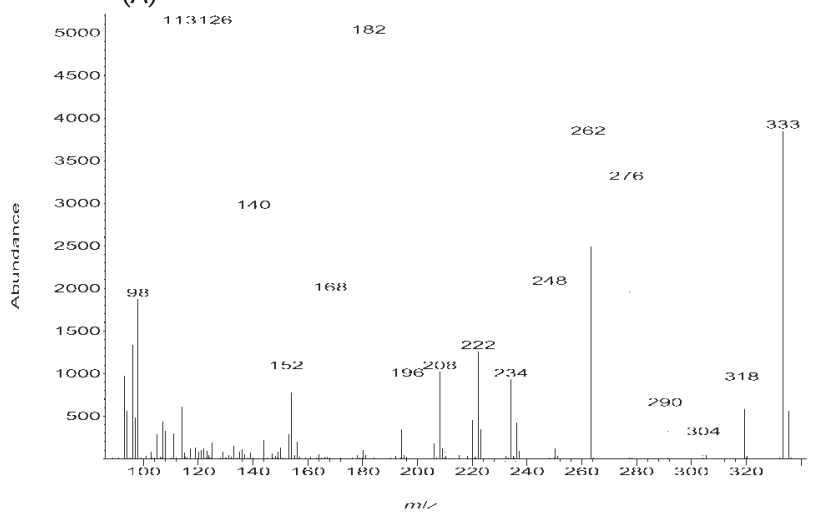

(B)

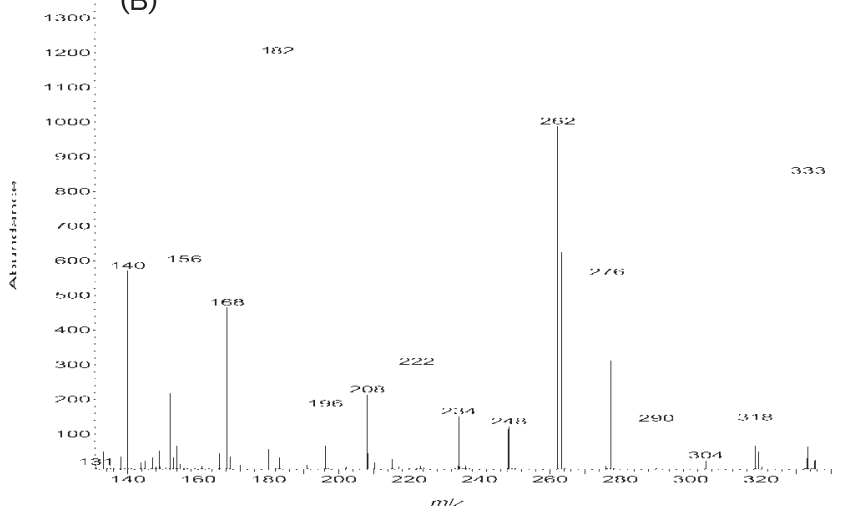

Fig. 3. Mass spectra of 4,4-dimethyloxazoline derivatives of $(A)$ cis-9,trans-11 CLA (rumenic acid; RA) and (B) trans-9,trans-11 CLA synthesized from linoleic acid (LA) during $4 \mathrm{~h}$ incubations with suspensions of mixed faecal bacteria. Relative abundance of ion fragments at $\mathrm{m} / \mathrm{z} 262$ and 263 indicate that ${ }^{2} \mathrm{H}$ is located on C-13 of the fatty acid moiety.

was similar to that of mixed microbiota, indicating that labelling was located on C-13 (spectra not shown). However, the spectra of the DMOX derivative of trans9, trans-11-CLA were less informative. Ion fragments corresponding to C-13 ( $/ \mathrm{m} / \mathrm{z} 262$ and 263) appeared to indicate small amounts of label in the product from $P$. freudenreichii subsp. shermanii, whereas the trans-9,trans11-CLA peak in Bif. breve samples contained a higher enrichment than RA. It is possible that, because trans9, trans-11-CLA and trans-10,trans-12-CLA co-elute during GC analysis, the labelling pattern was due to the contributions of both CLA isomers.

Enrichment of VA was comparable for all four VAproducing species, Bu. fibrisolvens, Ros. hominis, Ros. inulinivorans and Rum. obeum (Table 2). The $\mathrm{m}+1$ isotopomers had an MPE ratio of $0.879-0.941$ relative to water, while the ratio for $\mathrm{m}+2$ isotopomers varied between 0.214 and 0.303 . There was no evidence of labelling at $m+3$. Mass spectra of DMOX derivatives of VA revealed a clear pattern of labelling in ion fragments of $\mathrm{m} / \mathrm{z} 210$ and 211 that was absent at $\mathrm{m} / z$ of 196 and 197 (Fig. 4). Low abundances of ions corresponding to C-10 to C-12 of the fatty acid moiety did not permit discrimination between singly- and doubly-labelled ion fragments. Thus, the DMOX spectrum in Fig. 4 clearly indicates a label located on C-9 of VA. Furthermore, the relative abundance of ions at $\mathrm{m} / z$ 264, 265 and 266 also suggests additional enrichment at C-13, which would have arisen from reduction of the labelled VA precursor. Comparison of the ratio of ions at $m / z 211 / 210$ and 265/264 is consistent with this conclusion.

\section{Metabolism of ricinoleic acid in mixed and pure cultures}

Ricinoleic acid was metabolized rapidly by mixed faecal bacteria, $>80 \%$ of an initial concentration of $500 \mathrm{mg} \mathrm{l}^{-1}$ being lost in $8 \mathrm{~h}$ (not shown). No CLA isomers, VA or oleic acid were liberated during incubation with ricinoleic acid. Products formed eluted with a retention time close to that of ricinoleic acid. GC-MS analysis of FAME revealed the occurrence of abundant ion fragments consistent with the presence of a hydroxyl group, but due to the inability to detect the molecular ion or ion fragments in the high $\mathrm{m} / \mathrm{z}$ region it was not possible to identify unequivocally the structure of the compounds formed. The pure cultures used in the present study did not metabolize ricinoleic acid.

\section{DISCUSSION}

Findings from this study advance the understanding of LA metabolism by human intestinal bacteria in three main respects. Firstly, RA is the main CLA formed in the mixed microbiota, while other geometric 9,11 isomers are also significant products but trans-10,cis-12-CLA is a minor metabolite. Secondly, the 9,11 isomers are formed in the mixed microbiota by a mechanism that results in the incorporation of a $\mathrm{H}$ atom from water at C-13. Thirdly, pure cultures produce RA and VA from LA by a mechanism similar to that in the mixed human intestinal microbiota, although the synthesis of minor CLA isomers may arise via different mechanisms for particular bacterial species. The results also indicate that, despite the large differences in the composition of the microbial communities in the human intestine and the rumen (Edwards et al., 2004; Eckburg et al., 2005), and the presence of an additional route of RA synthesis via a HFA in the human intestine (Devillard et al., 2007), the final labelling patterns of CLA isomers formed by the two ecosystems are similar.

Evidence of CLA formation by intestinal bacteria was first obtained indirectly in the experiments of Chin et al. (1994), who noted that germ-free rats had a lower incorporation of 
Table 2. Metabolism of LA and deuterium enrichment in products following growth of pure cultures of intestinal bacteria in medium enriched with deuterium oxide

The initial concentration of LA was $50 \mathrm{mg}^{-1}$. No LA was detected after $24 \mathrm{~h}$ incubation in any sample. The mean MPE enrichment in water was 45.2, SEM 1.25. Values are means \pm SE ( $n=3$ ) after $24 \mathrm{~h}$ incubations with LA. Blank cells mean that, due to the low concentration of the fatty acid, the MPE value could not be measured.

\begin{tabular}{|c|c|c|c|c|c|c|c|c|c|c|c|c|c|c|}
\hline \multirow[b]{3}{*}{ Bacterium } & \multicolumn{14}{|c|}{ Concentration $\left(\mathrm{mg} \mathrm{l}^{-1}\right)$} \\
\hline & \multicolumn{2}{|c|}{ cis-9,trans-11 (RA) } & \multicolumn{2}{|c|}{ trans-9,cis-11 } & \multicolumn{2}{|c|}{ trans-10, cis-12 } & \multicolumn{2}{|c|}{ cis-9,cis-11 } & \multicolumn{2}{|c|}{ trans-9,trans-11 } & \multicolumn{2}{|c|}{ VA } & & \\
\hline & Mean & $\mathrm{SE}$ & Mean & $\mathrm{SE}$ & Mean & $\mathrm{SE}$ & Mean & SE & Mean & $\mathrm{SE}$ & Mean & $\mathrm{SE}$ & & \\
\hline Bif. breve & 25.7 & 2.75 & 0.41 & 0.116 & 0.03 & 0.024 & 0.54 & 0.034 & 9.96 & 2.392 & 0 & 0 & & \\
\hline Bu. fibrisolvens & 0.37 & 0.108 & 0.0 & 0.00 & 0 & 0 & 0 & 0 & 0.54 & 0.211 & 28.2 & 0.64 & & \\
\hline $\begin{array}{l}\text { P. freudenreichii } \\
\text { subsp. shermanii }\end{array}$ & 37.6 & 0.96 & 0.18 & 0.018 & 3.17 & 0.109 & 0.43 & 0.028 & 2.26 & 0.098 & 0 & 0 & & \\
\hline Ros. hominis & 0 & 0 & 0 & 0 & 0 & 0 & 0 & 0 & 0.40 & 0.090 & 23.5 & 0.29 & & \\
\hline Ros. inulinivorans & 0.30 & 0.090 & 0.26 & 0.018 & 0 & 0 & 0 & 0 & 0.24 & 0.027 & 34.9 & 5.08 & & \\
\hline \multirow[t]{4}{*}{ Rum. obeum } & 0.67 & 0.052 & 0.0 & 0.00 & 0 & 0 & 0 & 0 & 0.74 & 0.186 & 20.9 & 3.10 & & \\
\hline & \multicolumn{14}{|c|}{ MPE ratio (MPE in CLA isomer/MPE in water) } \\
\hline & \multicolumn{2}{|c|}{ cis-9,trans-11 (RA) } & \multicolumn{2}{|c|}{ trans-10,cis-12 } & \multicolumn{2}{|c|}{ cis-10,trans-12 } & \multicolumn{2}{|c|}{ trans-9,trans-11 } & \multicolumn{2}{|c|}{$\mathrm{VA}, \mathrm{m}+1$} & \multicolumn{2}{|c|}{$\mathrm{VA}, \mathrm{m}+2$} & \multicolumn{2}{|c|}{$\mathrm{VA}, \mathrm{m}+3$} \\
\hline & Mean & $\mathrm{SE}$ & Mean & $\mathrm{SE}$ & Mean & $\mathrm{SE}$ & Mean & SE & Mean & SE & Mean & $\mathrm{SE}$ & Mean & SE \\
\hline Bif. breve & 0.632 & 0.0370 & & & & & 0.990 & 0.0293 & & & & & & \\
\hline Bu. fibrisolvens & & & & & & & & & 0.941 & 0.0355 & 0.274 & 0.0259 & 0 & 0 \\
\hline $\begin{array}{l}\text { P. freudenreichii } \\
\text { subsp. shermanii }\end{array}$ & 0.601 & 0.0254 & 0 & 0 & & & 0.595 & 0.0488 & & & & & & \\
\hline Ros. hominis & & & & & & & & & 0.915 & 0.0329 & 0.224 & 0.0084 & 0 & 0 \\
\hline Ros. inulinivorans & & & & & & & & & 0.934 & 0.0053 & 0.303 & 0.0226 & 0 & 0 \\
\hline Rum. obeum & & & & & & & & & 0.879 & 0.0116 & 0.214 & 0.0248 & 0 & 0 \\
\hline
\end{tabular}



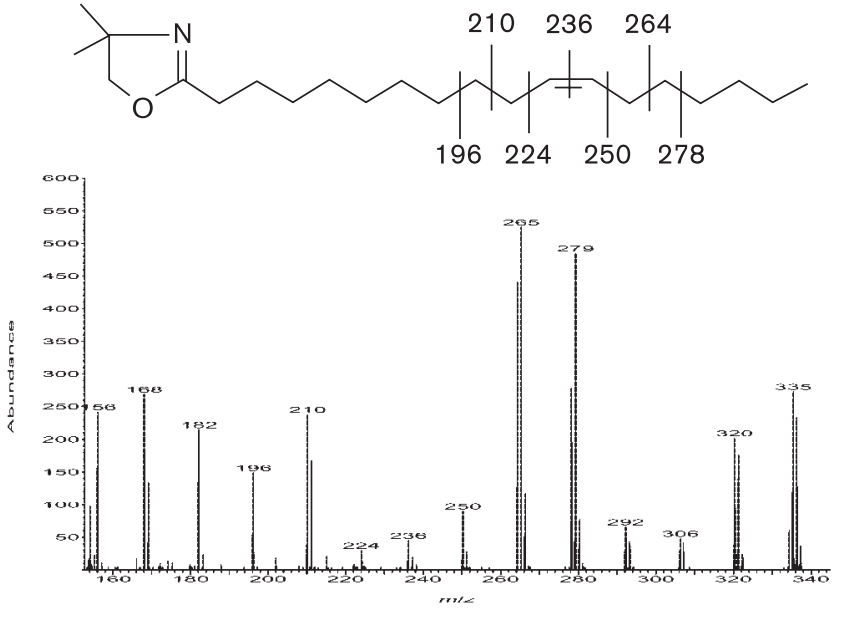

Fig. 4. Mass spectrum of 4,4-dimethyloxazoline derivative of VA produced from LA by Ros. inulinovorans. Relative abundance of ion fragments at $\mathrm{m} / \mathrm{z} 210$ and 211 indicates that ${ }^{2} \mathrm{H}$ is located on C-9 of the fatty acid moiety. Comparison of ion fragments at $\mathrm{m} / \mathrm{z}$ 264,265 and 266 reveals additional enrichment of ${ }^{2} \mathrm{H}$ on $\mathrm{C}-13$ of the fatty acid moiety. Bu. fibrisolvens, Ros. hominis and Rum. obeum gave similar spectra.

CLA in liver, lung, kidney, skeletal muscle and abdominal adipose tissue than conventional animals. Kamlage et al. $(1999,2000)$ measured the ability of faecal suspensions to produce CLA from LA, but did not identify the structure of CLA isomers formed. This study provides unequivocal evidence that RA is the main CLA produced during LA metabolism by the human intestinal microbiota, with lower amounts of trans-9, trans-11-CLA also being formed. Other isomers, including trans-10,cis-12-CLA, were only minor products. This is a significant finding, since the antiproliferative and anti-inflammatory properties of RA are well established (Ha et al., 1987; Pariza, 2004; Wahle et al., 2004; Bauman et al., 2005), while the physiological effects of trans-10,cis-12-CLA on gut health are potentially less beneficial (Kritchevsky, 2000; Pariza, 2004). Far fewer data are available on the role of trans-9,trans-11-CLA, but in vitro studies with various human cell lines point towards this isomer exhibiting activity similar to or higher than RA (Coakley et al., 2006).

CLA formation has been studied in three other groups of bacteria, namely ruminal bacteria, lactic acid producers predominantly from dairy products, and Propionibacterium acnes. RA, trans-9,trans-11-CLA and trans-10,cis-12-CLA were the major CLA intermediates formed from LA in ruminal digesta, with traces of trans-9,cis-11-CLA, cis-9,cis11-CLA and cis-10,cis-12-CLA (Wallace et al., 2007). In contrast, trans-10,cis-12-CLA was formed in only trace quantities by the human intestinal microbiota. In the rumen, the ratio of isomers formed seems to depend on $\mathrm{pH}$ (Choi et al., 2005), possibly because different bacterial species producing various isomers have specific ranges in
$\mathrm{pH}$ for optimal growth. It is possible that this may also hold true for bacteria in the human intestine. The CLA isomers formed by human intestinal bacteria contrast even more with those produced during LA metabolism by Lactobacillus plantarum and related species, where trans9, trans-11-CLA is often the most abundant isomer formed (Ogawa et al., 2001, 2005). P. acnes, by contrast, produces only trans-10,cis-12 CLA (Liavonchanka et al., 2006). The formation of CLA by $P$. freudenreichii subsp. shermanii reported here appears to be unique thus far, in that both 9,11 and 10,12 geometric isomers are formed, indicating that the two mechanisms of CLA formation are not mutually exclusive. It would be important to understand the regulation of both synthetic pathways in the same organism.

Mass spectrometric analysis indicated that a deuterium atom from deuterated water was incorporated into C-13 of RA and trans-9,trans-11-CLA in both mixed human microbiota and pure cultures. Bacteria that converted LA to VA had a labelling pattern suggesting that this was derived via the reduction of a C-13-labelled RA intermediate. Concentrations of trans-10,cis-12-CLA were too low in the mixed microbiota to make an assessment of labelling, but data from incubations of LA with pure cultures indicated that the labelling of trans-10,cis-12-CLA was much lower compared with RA. This is a pattern that has been observed previously in pure and mixed cultures of ruminal bacteria (Kepler et al., 1971; Wallace et al., 2007).

The labelling pattern provides an indication of the enzymic mechanism of CLA formation. CLA could be formed by a direct isomerization (Liavonchanka et al., 2006), a hydration/dehydration mechanism (Ogawa et al., 2001, 2005), or a hydrogen-abstraction mechanism involving a radical intermediate (Wallace et al., 2007). From the data presented here and from elsewhere (Liavonchanka et al., 2006; Wallace et al., 2007), it seems clear that 10,12 CLA isomers are formed by an isomerase mechanism that does not involve proton exchange with water. The mechanism of RA formation remains uncertain, however. Our original interpretation of the labelling pattern from ruminal bacteria (Wallace et al., 2007), which is very similar to that found here with human intestinal bacteria, was that RA synthesis proceeded with no hydroxy intermediate, resulting in labelling on C-13 (Fig. 5A). The fatty acid that we considered the most likely intermediate of a hydration/ dehydration mechanism, ricinoleic acid (12-OH-18:1), was not converted to RA in the rumen. A hydrogenabstraction mechanism with a radical intermediate was therefore proposed (Wallace et al., 2007). That the same pattern occurs in the mixed intestinal microbiota, where some species form $10-\mathrm{OH}-18: 1$ that in turn other species convert to RA, is consistent with two possible interpretations. One is that the direct mechanism predominated over the cross-species hydration/dehydration one, with the latter being undetectable. The other is that the $10-\mathrm{OH}-18: 1$ is metabolized also by a hydrogen-abstraction mechanism (Fig. 5B). Indeed, it is tempting to speculate that, in those 
A. Possible hydrogen-abstraction mechanism of rumenic acid formation<smiles>[R]C/C=C\C/C=C\C[R]</smiles>

linoleic acid<smiles>[R]C/C=C\C1=C2CCCC2CC1</smiles>

rearrangement<smiles>[R]C/C=C\C=C/C[R]</smiles>

protonation<smiles>[R]C/C=C\C=C/C[R]</smiles>

cis-9, trans-11-CLA

B. Possible hydration-dehydration mechanism of rumenic acid formation<smiles>[R]C/C=C\C/C=C\CC(O)CC[R]</smiles><smiles>CCCCCCCC</smiles><smiles>[R]CCC(O)C1C=C2CCCC2[R]C1</smiles>
rearrangement<smiles>[R]CC=CC(O)CC[R]</smiles><smiles>[R]C/C=C/C(O)CC[R]</smiles><smiles>CO</smiles><smiles>[R]C/C=C\C=C/C[R]</smiles><smiles>[R]C/C=C/C=C/C[R]</smiles>

$\mathrm{R}=\mathrm{C}_{5} \mathrm{H}_{11} \quad \mathrm{R}^{\prime}=\mathrm{C}_{7} \mathrm{H}_{13} \mathrm{O}_{2}$

cis-9, trans-11-CLA

Fig. 5. Two potential mechanisms of RA formation. Both involve the abstraction of $\mathrm{H}$ from $\mathrm{C}-11$, with a rearrangement that leads to the assimilation of $\mathrm{H}$ from water on $\mathrm{C}-13$. The 'direct' mechanism $(\mathrm{A})$ involves no hydroxy intermediate. The hydration/ dehydration mechanism involves firstly the formation of $10-\mathrm{OH}-18: 1$, from which $\mathrm{H}$ at $\mathrm{C}-11$ is abstracted and hydration then occurs (B). The mechanisms could occur in two species (two sets of brackets), or possibly within a single species.

species that form RA and/or VA, 10-OH-18: 1 is a transient intermediate that has not yet been detected. Thus, the unlikely scenario that some species of Roseburia metabolize LA by one route (the 'direct' route to RA then VA), while others metabolize LA by another (to $10-\mathrm{OH}-18: 1$ ) (Devillard et al., 2007), would no longer be required. In the latter case, all Roseburia spp. would form $10-\mathrm{OH}-18: 1$, with only some species continuing the metabolism further by the rearrangement mechanism. However, the finding that VA-producing species do not metabolize 10-OH-18:1 to RA or VA tends to favour the former interpretation, of a predominant direct mechanism.

The major difference between the involvement of 10-OH18:1 in CLA formation by L. plantarum and by human intestinal bacteria is that the $12-\mathrm{OH}-18: 1$ fatty acid, ricinoleic acid, could be used to form RA in the former (Ando et al., 2003) but not the latter species (Devillard et al., 2007). Whether this indicates that the systems are fundamentally different, or only that $L$. plantarum has additional enzymic potential to metabolize ricinoleic acid to another precursor of CLA formation, is unclear at this stage.

It is concluded that, even though the microbial species responsible for LA metabolism in the human intestine and the rumen are significantly different, and more than one route for RA synthesis is known in the former, the predominant mechanisms of CLA and VA formation in the two gut ecosystems are similar. RA formation in both ecosystems may involve the action of radical enzymes that abstract $\mathrm{H}$ atoms from the conjugated double bond system.

\section{ACKNOWLEDGEMENTS}

The Rowett Research Institute receives funding from the Rural and Environment Research and Analysis Directorate (RERAD) of the Scottish Government. Collaboration was funded by the EC Framework 6 Integrated Project, 'LIPGENE' and by the Royal Society of Edinburgh. We thank Maureen Annand, David Brown 
and Eric Milne for technical assistance and expertise. Gerald Lobley and Grietje Holtrop offered invaluable advice for which the authors are extremely grateful. We thank Nest McKain and Sylvia Duncan for help and advice.

\section{REFERENCES}

Ando, A., Ogawa, J., Kishino, S. \& Shimizu, S. (2003). CLA production from ricinoleic acid by lactic acid bacteria. J Am Oil Chem Soc 80, 889-894.

Barcenilla, A., Pryde, S. E., Martin, J. C., Duncan, S. H., Stewart, C. S., Henderson, C. \& Flint, H. J. (2000). Phylogenetic relationships of butyrate-producing bacteria from the human gut. Appl Environ Microbiol 66, 1654-1661.

Bassaganya-Riera, J., Hontecillus, R. \& Beitz, D. C. (2002). Colonic anti-inflammatory mechanisms of conjugated linoleic acid. Clin Nutr 21, 451-459.

Bassaganya-Riera, J., Reynolds, K., Martino-Catt, S., Cui, Y. Z., Hennighausen, L., Gonzalez, F., Rohrer, J., Benninghoff, A. U. \& Hontecillas, R. (2004). Activation of PPAR gamma and delta by conjugated linoleic acid mediates protection from experimental inflammatory bowel disease. Gastroenterology 127, 777-791.

Bauman, D. E., Lock, A. L., Corl, B. A., Ip, C., Salter, A. M. \& Parodi, P. M. (2005). Milk fatty acids and human health: potential role of conjugated linoleic acid and trans fatty acids. In Ruminant Physiology: Digestion, Metabolism and Impact of Nutrition on Gene Expression, Immunology and Stress, pp. 529-561. Edited by K. Serjrsen, T. Hvelplund \& M. O. Nielsen. Wageningen, The Netherlands: Wageningen Academic Publishers.

Campbell, I. M. (1974). Incorporation and dilution values - their calculation in mass spectrally stable isotope labeling experiments. Bioorg Chem 3, 386-397.

Chanoine, J. P., Hampl, S., Jensen, C., Boldrin, M. \& Hauptman, J. (2005). Effect of orlistat on weight and body composition in obese adolescents - a randomized controlled trial. JAMA 293, 2873-2883.

Chin, S. F., Storkson, J. M., Albright, K. J. \& Pariza, M. W. (1994). Conjugated linoleic acid (9,11-octadecadienoic and 10,12-octadecadienoic acid) is produced in conventional but not germ-free rats fed linoleic-acid. J Nutr 124, 694-701.

Choi, N. J., Imm, J. Y., Oh, S., Kim, B. C., Hwang, H. J. \& Kim, Y. J. (2005). Effect of $\mathrm{pH}$ and oxygen on conjugated linoleic acid (CLA) production by mixed rumen bacteria from cows fed high concentrate and high forage diets. Anim Feed Sci Technol 123-124, 643-653.

Coakley, M., Ross, R. P., Nordgren, M., Fitzgerald, G., Devery, R. \& Stanton, C. (2003). Conjugated linoleic acid biosynthesis by humanderived Bifidobacterium species. J Appl Microbiol 94, 138-145.

Coakley, M., Johnson, M. C., McGrath, E., Rahman, S., Ross, R. P., Fitzgerald, G. F., Devery, R. \& Stanton, C. (2006). Intestinal bifidobacteria that produce trans-9,trans-11 conjugated linoleic acid: a fatty acid with antiproliferative activity against human colon SW480 and HT-29 cancer cells. Nutr Cancer 56, 95-102.

Devillard, E., McIntosh, F. M., Duncan, S. H. \& Wallace, R. J. (2007). Metabolism of linoleic acid by human gut bacteria: different routes for biosynthesis of conjugated linoleic acid. J Bacteriol 189, 25662570 .

Duncan, S. H., Aminov, R. I., Scott, K. P., Louis, P., Stanton, T. B. \& Flint, H. J. (2006). Proposal of Roseburia faecis sp. nov., Roseburia hominis sp. nov. and Roseburia inulinivorans sp. nov., based on isolates from human faeces. Int J Syst Evol Microbiol 56, 2437-2441.

Duncan, S. H., Louis, P. \& Flint, H. J. (2007). Cultivable bacterial diversity from the human colon. Lett Appl Microbiol 44, 343-350.
Eckburg, P. B., Bik, E. M., Bernstein, C. N., Purdom, E., Dethlefsen, L., Sargent, M., Gill, S. R., Nelson, K. E. \& Relman, D. A. (2005). Diversity of the human intestinal microbial flora. Science 308, 1635-1638.

Edwards, J. E., McEwan, N. R., Travis, A. J. \& Wallace, R. J. (2004). $16 \mathrm{~S}$ rDNA library-based analysis of ruminal bacterial diversity. Antonie Van Leeuwenhoek 86, 263-281.

Ha, Y. L., Grimm, N. K. \& Pariza, M. W. (1987). Anticarcinogens from fried ground beef: heat-altered derivatives of linoleic acid. Carcinogenesis 8, 1881-1887.

Harfoot, C. G. \& Hazlewood, G. P. (1997). Lipid metabolism in the rumen. In The Rumen Microbial Ecosystem, pp. 382-426. Edited by P. N. Hobson \& C. S. Stewart. London: Chapman \& Hall.

Hauptman, J., Lucas, C., Boldrin, M. N., Collins, H. \& Segal, K. R. (2000). Orlistat in the long-term treatment of obesity in primary care settings. Arch Fam Med 9, 160-167.

Herbert, D., Phipps, P. J. \& Strange, R. E. (1971). Chemical analysis of microbial cells. Methods Microbiol 5B, 209-304.

Hobson, P. N. (1969). Rumen bacteria. Methods Microbiol 3B, 133139.

Kamlage, B., Hartmann, L., Gruhl, B. \& Blaut, M. (1999). Intestinal microorganisms do not supply associated gnotobiotic rats with conjugated linoleic acid. J Nutr 129, 2212-2217.

Kamlage, B., Hartmann, L., Gruhl, B. \& Blaut, M. (2000). Linoleic acid conjugation by human intestinal microorganisms is inhibited by glucose and other substrates in vitro and in gnotobiotic rats. J Nutr 130, 2036-2039.

Kemp, M. Q., Jeffy, B. D. \& Romagnolo, D. F. (2003). Conjugated linoleic acid inhibits cell proliferation through a p53-dependent mechanism: effects on the expression of G1-restriction points in breast and colon cancer cells. J Nutr 133, 3670-3677.

Kepler, C. R., Tucker, W. P. \& Tove, S. B. (1971). Biohydrogenation of unsaturated fatty acids. V. Stereospecificity of proton addition and mechanism of action of linoleic acid $\Delta^{12}$-cis, $\Delta^{11}$-trans-isomerase from Butyrivibrio fibrisolvens. J Biol Chem 246, 2765-2771.

Kritchevsky, D. (2000). Antimutagenic and some other effects of conjugated linoleic acid. Br J Nutr 83, 459-465.

Liavonchanka, A., Hornung, E., Feussner, I. \& Rudolph, M. G. (2006). Structure and mechanism of the Propionibacterium acnes polyunsaturated fatty acid isomerase. Proc Natl Acad Sci U S A 103, 2576-2581.

Nichenametla, S. N., South, E. H. \& Exon, J. H. (2004). Interaction of conjugated linoleic acid, sphingomyelin, and butyrate on formation of colonic aberrant crypt foci and immune function in rats. J. Toxicol Environ Health. Part A 67, 469-481.

Ogawa, J., Matsumura, K., Kishino, S., Omura, Y. \& Shimizu, S. (2001). Conjugated linoleic acid accumulation via 10-hydroxy-12octadecaenoic acid during microaerobic transformation of linoleic acid by Lactobacillus acidophilus. Appl Environ Microbiol 67, 12461252.

Ogawa, J., Kishino, S., Ando, A., Sugimoto, S., Mihara, K. \& Shimizu, S. (2005). Production of conjugated fatty acids by lactic acid bacteria. $J$ Biosci Bioeng 100, 355-364.

Pariza, M. W. (2004). Perspective on the safety and effectiveness of conjugated linoleic acid. Am J Clin Nutr 79, 1132S-1136S.

Polan, C. E., McNeill, J. J. \& Tove, S. B. (1964). Biohydrogenation of unsaturated fatty acids by rumen bacteria. J Bacteriol 88, 1056-1064.

Rumney, C. J., Duncan, S. H., Henderson, C. \& Stewart, C. S. (1995). Isolation and characteristics of a wheatbran-degrading Butyrivibrio from human faeces. Lett Appl Microbiol 20, 232-236.

Van Niel, C. B. (1928). The Propionic Acid Bacteria. Haarlem, The Netherlands: J. W. Boissevain. 
Wahle, K. W., Heys, S. D. \& Rotondo, D. (2004). Conjugated linoleic acids: are they beneficial or detrimental to health? Prog Lipid Res 43, 553-587.

Wallace, R. J., Chaudhary, L. C., McKain, N., McEwan, N. R., Richardson, A. J., Vercoe, P. E., Walker, N. D. \& Paillard, D. (2006). Clostridium proteoclasticum: a ruminal bacterium that forms stearic acid from linoleic acid. FEMS Microbiol Lett 265, 195-201.
Wallace, R. J., McKain, N., Shingfield, K. J. \& Devillard, E. (2007). Isomers of conjugated linoleic acids are synthesized via different mechanisms in ruminal digesta and bacteria. J Lipid Res 48, 22472254.

Edited by: D. M. Gordon 